\title{
Contract Optimization of Renewable Energy Electricity Supply Chain on the Island for Sustainability
}

\author{
Bo Jiang \\ Institute of Logistics Science and Engineering Research, Shanghai Maritime University, Shanghai, China \\ Email: kibenjiang@163.com
}

How to cite this paper: Jiang, B. (2021). Contract Optimization of Renewable Energy Electricity Supply Chain on the Island for Sustainability. Open Journal of Business and Management, 9, 3053-3075.

https://doi.org/10.4236/ojbm.2021.96171

Received: October 19, 2021

Accepted: November 27, 2021

Published: November 30, 2021

Copyright (c) 2021 by author(s) and Scientific Research Publishing Inc. This work is licensed under the Creative Commons Attribution International License (CC BY 4.0).

http://creativecommons.org/licenses/by/4.0/

(c) (i) Open Access

\begin{abstract}
In China, a large number of islands with power demand have not developed renewable energy, and their power supply has long been dependent on fossil fuels. In this paper, the author assumes that the supply and demand for electricity are uncertain, and consider an island electricity supply chain consisting of a single intermittent renewable plant and a single electricity sales company (ESC) and introduce Stackelberg game theory into it. In this case, the author studies how to improve the power supply efficiency and promote the development of renewable energy under the main power generation way of renewable energy, also analyzes the influence of different parameters on the decision-making of supply chain participants. Through comparative analysis, it can be found that the efficiency of supply chain and the development of renewable energy resources are significantly improved after the introduction of revenue sharing contract and revenue and risk sharing contract, and the effect of the latter contract is more obvious. Furthermore, the research shows that to maintain high levels of installed capacity in renewable energy, the efficiency of electricity generation equipment is not always the higher the better. And the research also reminds governments to take full account of the contractual environment of the electricity supply chain when subsidizing renewable energy.
\end{abstract}

\section{Keywords}

Renewable Energy Sources, Supply Chain Coordination, Random Yield and Demand, Contract Optimization

\section{Introduction}

In recent years, with the traditional energy crisis and environmental pollution 
becoming more serious, the development of green and clean energy has become the consensus of all countries in the world. As the largest carbon emitter, China's actions in reducing carbon emissions have received widespread attention. In response to the emission reduction target, the government is vigorously developing and utilizing renewable energy from the mainland and inhabited islands, mainly used for renewable energy electricity generation.

However, renewable energy generation on islands faces some problems. For example, renewable energy generation is intermittent and the electricity demand of customers is uncertain. In order to maintain the flexibility of renewable energy generation on islands and realize dynamic adjustment of installed capacity, the wholesale price of electricity on the island is not fixed, while the retail price of electricity is regulated by government guidance. In addition, the Chinese government issued a new electricity system reform plan in 2015. However, the reform plan is mainly for mainland areas, and the island region has not yet formed a perfect electricity market mechanism. In this context, this paper establishes an island electricity supply chain optimization model based on Stackelberg game, and analyzes how to improve the efficiency of renewable energy development and enhance the profit level of the whole supply chain. Furthermore, this paper also discusses the influence of some parameters on the decision variables of supply chain members.

Compared with other papers, this paper regards renewable energy power generation as the main power generation mode in the island environment, and uses economic theory to analyze and study. Relevant research results can provide theoretical reference for large-scale renewable energy power generation in remote island areas of China, including how to choose installed capacity of renewable energy generators and how to improve the efficiency of the power supply chain. This research, however, is subject to several limitations. First, in order to transform the complex reality into a mathematical model, this paper makes some simplification when designing the model, and this treatment can ensure the reliability and practical significance of the research. The second limitation concerns the numerical experiment, due to the lack of means to obtain real data, this paper uses simulation data in the numerical experiment, but it is worth noting that this will not affect the research conclusion.

The remainder of the study is organized as follows. In the next section, the author first reviews the most relevant literature and positions the paper with respect to the literature to highlight contributions. Section 3 describes the assumptions and notations for modeling the problem, and develops a centralized supply chain model as the benchmark. In Section 4, the decision-making model of decentralized supply chain is constructed. Section 5 presents detailed numerical discussions to compare the equilibrium decisions and profits under different contracts. In the last section, conclusions are given and possible future research directions are outlined. 


\section{Literature Review}

The work is primarily related to the analytical research on the renewable electricity, which is divided into three streams of research, namely, unreliable supply and yield uncertainty problems, Stackelberg game led by generator/manufacturer, and supply chain coordination. The following subsections discuss these streams.

\subsection{Supply Chain under Uncertainty}

To solve the uncertainty of renewable energy, a collaborative supply chain can be built to study the related problems (Chong \& Zhou, 2014). Many scholars have studied this kind of uncertain supply chain. Mardan et al. (2015) studied the countless emergency order of empirical decision problem, for this reason, they set up a cycle, product integration model of inventory and production plan, and puts forward a flexible backup purchasing plan based on inventory reserve, and it also shows in the uncertain environment emergency production plan decision effectiveness. Begen et al. (2016) examined the impact of supply uncertainty, demand uncertainty, and uncertainty reduction efforts on output and total costs. However, the research objects of these studies are industrial products, and the uncertainty of this supply chain is quite different from that of the electricity supply chain. On the one hand, the uncertainty of manufacturing production can be intervened manually. On the other hand, the supply uncertainty of the manufacturing industry can generally be classified as the advance uncertainty, and the uncertainty is a random fluctuation based on a certain quantity. Fortunately, researchers have studied the electricity supply chain under uncertain production and demand conditions. Xie et al. (2018) studied renewable energy electricity pricing strategies in competitive hybrid electricity markets with uncertain supply and demand. Kong et al. (2017) designed and studied the capacity investment model in the case of low renewable energy penetration and optimized the investment capacity.

\subsection{Stackelberg Game Led by Generator/Manufacturer}

In the island environment, renewable energy is the main way to generate electricity, so the renewable energy generator will become the leader of the supply chain. In the game model of Yu et al. (2020), manufacturers determine the wholesale price and emission reduction level as the leader, while retailers determine the retail price as the follower. They found that consumers' environmental awareness and tax rate have a significant impact on emission reduction. Xu et al. (2012) pointed out that in the single-cycle two-stage supply chain dominated by manufacturers, manufacturers can remedy the inaccurate inventory records through technology improvement strategies. In fact, in a two-stage supply chain structure, the dominant member is often able to obtain higher profits, Nielsen et al. (2019) prove this point by constructing a decision support framework that 
considers the green level, taking into account both game structures, manufacturers dominate and retailers dominate. The results show that when manufacturers dominate, they get higher profits and higher green level, while on the contrary, retailers get higher profits and higher green level. However, the above models are difficult to apply directly to renewable energy problems. There are few large-scale storage phenomena in the electricity supply, and there is no shortage of goods. In addition, due to the long investment cycle of renewable energy, it is unable to carry out the transformation of product lines, so the research on renewable energy focuses more on the investment in efficiency and capacity planning.

\subsection{Supply Chain Coordination}

In the supply chain, "double marginalization" is a problem that cannot be ignored (Li et al., 2013; Fang, 2018; Giri \& Bardhan, 2017; Luo et al., 2018), and supply chain coordination can be achieved by introducing appropriate contracts in the supply chain (Agnolucci, 2007), this is also an important research content of the study. Many scholars have done a lot of research on supply chain contract. Cachon and Lariviere (2005) introduced the revenue-sharing contract commonly used in video rentals into the supply chain model, demonstrated that revenue-sharing can coordinate the supply chain, and pointed out the limitations of revenue-sharing to explain why the contract could not be applied to all industries. On their basis, Chinese scholar Wu et al. (2020) further studied the dualchannel reverse supply chain with online and offline recycling channels. Through the case analysis of the model, they found that the revenue sharing contract could make the profit of recycling enterprises not lower than the profit under decentralized decision-making. Besides, there are a variety of contracts including repurchase contracts (Glock et al., 2020), risk sharing contracts (Scheller-Wolf \& Tayur, 2009) and quantitative flexible contracts (Tsay, 1999) that can be used to coordinate the supply chain.

Different from the previous researchers, in the study of the power supply chain, this paper pays attention to multiple decision-making behaviors of the intermittent renewable plant, including the optimal investment decision of renewable energy and the optimal wholesale price decision. In addition, this paper studies the electricity supply chain led by the intermittent renewable plant under the condition of double uncertainty of supply and demand. At present, most researchers regard renewable energy generators as followers in the electricity supply chain, while few scholars regard renewable energy generators as dominant players in the electricity supply chain. Finally, under the research framework of this paper, the coordination of supply chain still depends on the introduction of contract. However, the slight difference is that the research is progressive, starting with the introduction of a single contract and then adding a new contract based on that contract. 


\section{Model Setting and Benchmark}

\subsection{Notations and Assumptions}

This paper considers a supply chain consists of an intermittent renewable plant and an electricity sales company (ESC). In which the intermittent renewable plant determines the installed capacity of renewable energy $K$ and wholesale electricity price $w$ on the island. Due to the intermittent nature of renewable energy, there is uncertainty about the electricity output $q$. ESC decides the electricity purchased quantity $Q$ from intermittent renewable plant and has to sell the electricity at the government-guided retail price $p$. Taking the practicalities into consideration, consumers' demand for electricity, $X$, is full of uncertainty. In this case, the author builds a Stackelberg game model led by the intermittent renewable plant.

In order to improve readability, some notations will be useful. By summarizing the symbols used in this paper, we can get the following Table 1.

Table 1. Parameters and variables.

\begin{tabular}{|c|c|}
\hline Notation & Descriptions \\
\hline \multicolumn{2}{|c|}{ Parameter } \\
\hline$p$ & $\begin{array}{l}\text { The retail price of electricity determined by government guidance, } \\
p>w\end{array}$ \\
\hline$X$ & $\begin{array}{l}\text { Consumers demand for electricity follows a CDF of } F(x) \text {, and its PDF is } \\
f(x)\end{array}$ \\
\hline$y$ & $\begin{array}{l}\text { Electricity output density of renewable energy defined on the range }[0,1] \text {, } \\
\text { it follows a CDF of } H(y) \text {, and its PDF is } h(y)\end{array}$ \\
\hline$q$ & $\begin{array}{l}\text { Electricity output, it can be simplified as } q=\theta_{0} y K \text { where } \theta_{0} \text { is the } \\
\text { effective output coefficient }\end{array}$ \\
\hline$c$ & Unit installation cost of renewable energy \\
\hline$\phi$ & $\begin{array}{l}\text { Share ratio of ESC to intermittent renewable plant under revenue sharing } \\
\text { contract }\end{array}$ \\
\hline$g$ & Unit cost of emergency electricity generation \\
\hline 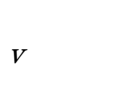 & $\begin{array}{l}\text { Unit compensation for unsold electricity of ESC under risk sharing } \\
\text { contract, } v<p(1-\phi)\end{array}$ \\
\hline$\mu$ & Government subsidies for unit grid-connected electricity \\
\hline \multicolumn{2}{|l|}{ Variable } \\
\hline$Q$ & Electricity purchased quantity \\
\hline$K$ & Installed capacity of renewable energy \\
\hline$w$ & Wholesale electricity price \\
\hline
\end{tabular}


All the supply chain members are risk-neutral, have information symmetry, and aim to maximize their own long-run expected profit. Fluctuations in renewable energy generation are independent of fluctuations in electricity demand. For this double fluctuation, referring to Adhikari et al. (2020), this paper defines two nonnegative, continuous functions to represent them. Due to the particularity of electricity and the geographical attribute of the island, residual value income in supply chain is not considered in this paper. Emergency electricity generation can be generated by consuming fossil fuels when the intermittent renewable plant fails to meet the electricity purchased quantity of ESC (Frydrychowicz-Jastrzebska, 2018), but this will require additional costs. On the other hand, when the electricity output is greater than the electricity purchased quantity of ESC, the intermittent renewable plant can abandon electricity by closing some units.

$\Pi_{q}, \Pi_{r}, \Pi_{s c}$ represents the expected profits of intermittent renewable plant, ESC and the whole supply chain respectively. In order to better represent the supply chain under different contracts, the paper uses the superscript " $T$ " to represent the supply chain under the wholesale price contract; the supply chain under revenue sharing contract is represented by the superscript "S"; the superscript "DS" denotes the supply chain under the revenue sharing-demand risk sharing contract.

Based on the motivations discussed in introduction, the author analyzes the following three scenarios, which are illustrated in Figure 1.

\subsection{Benchmark: Centralized Supply Chain}

In this benchmark case, the intermittent renewable plant and ESC in the electricity supply chain can be integrated as one enterprise, and the enterprise seeks to maximize the expected profits of the whole supply chain. The decision-making function with the goal of maximizing total profit is:

$$
\Pi_{s c}(Q, K)=p E(\min \{X, Q\})+\mu E\left(\min \left\{Q, \theta_{0} y K\right\}\right)-c K-g E\left(Q-\theta_{0} y K\right)^{+}
$$

In Equation (1), the first two items represent the income of the electricity supply chain from selling electricity and receiving government subsidies, the last two indicate the cost of electricity production.

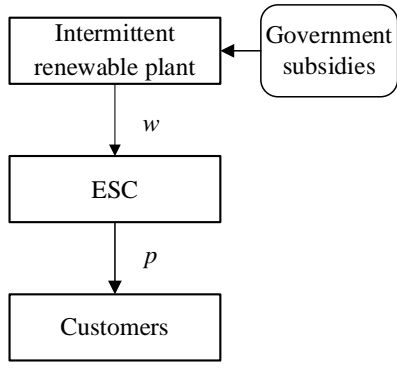

Mode T

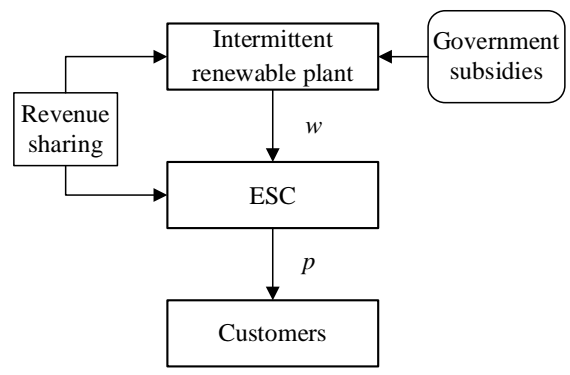

Mode S

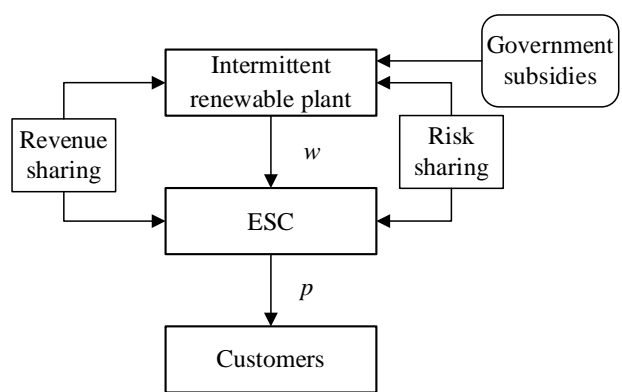

Mode DS

Figure 1. Illustration of three different scenarios. 
Proposition 1: Under the centralized supply chain, there is a set of optimal solutions $\left(Q^{*}, K^{*}\right)$ to maximize the expected profit of the whole supply chain and satisfy:

$$
\begin{gathered}
Q^{*}=F^{-1}\left[\frac{p+\mu-(g+\mu) H\left(\frac{Q^{*}}{\theta_{0} K^{*}}\right)}{p}\right] \\
\int_{0}^{\frac{Q^{*}}{\theta_{0} K^{*}}} y h(y) y h(y) \mathrm{d} y=\frac{c}{\theta_{0}(g+\mu)}
\end{gathered}
$$

For the remainder of this study, the paper denotes $z=\frac{Q}{\theta_{0} K}$ as the order level of the ESC, then it can be got $\int_{0}^{z^{*}} y h(y) \mathrm{d} y=\frac{c}{\theta_{0}(g+\mu)}$, and $z^{*}$ can be determined according to the parameters $c, \theta_{0}, g$ and $\mu$. Similarly, according to the relevant parameters and $F(x)$ and $H(y), Q^{*}$ can be determined. By combining $z^{*}$ and $Q^{*}, K^{*}$ will be got. At the same time, it can be easily proved that the installed capacity of renewable energy $K^{*}$ is positively correlated with the electricity purchased quantity when other parameters are fixed, which shows that in the electricity supply chain system under centralized decision-making, with the increase of electricity purchased quantity of the ESC, the intermittent renewable plant will also increase the installed capacity of renewable energy. This provides a theoretical basis for large-scale development of renewable energy electricity generation on the island, and also brings practical significance for the study of this paper.

In order to express the results more clearly and intuitively, according to Xie et al. (2019), the paper assumes that $X \sim U(m, n), \quad y \sim U(0,1)$, then it can be got:

$$
\left\{\begin{array}{l}
Q^{*}=\frac{\sqrt{2}(m-n)(g+\mu)+\theta_{0} \sqrt{\frac{g+\mu}{c \theta_{0}}}(p n+\mu n-m \mu)}{p \theta_{0} \sqrt{\frac{g+\mu}{c \theta_{0}}}} \\
K^{*}=\frac{2(m-n)(g+\mu)+\sqrt{2} \theta_{0} \sqrt{\frac{g+\mu}{c \theta_{0}}}(p n+\mu n-m \mu)}{2 p \theta_{0}}
\end{array}\right.
$$

Proposition 2: Under the centralized supply chain, the expected profit of the electricity supply chain $\Pi_{s c}(Q, K)$ is a jointly concave function of the electricity purchased quantity $Q$ and the installed capacity $K$.

After obtaining the optimal electricity purchased quantity $Q^{*}$ and the optimal installed capacity $K^{*}$, then the maximum expected profit of the electricity supply chain under centralized decision-making can be obtained. 


\section{Design and Analyze Supply Chain Contracts}

Under the background of the new electricity reform, the marketization reform of plant network separation and transmission and distribution separation is implemented, so the intermittent renewable plant and the ESC on the island constitute a decentralized supply chain. In this section the paper will introduce the wholesale price contract, revenue sharing contract and revenue and risk sharing contract respectively to analyze the strategic behavior of supply chain participants. In addition, under each contract, this paper will pay attention to the influence of a certain parameter on the decision variable. So to better illustrate this work, similar to the benchmark model, specific distribution functions will be introduced after the general results. The supply chain structure under three contracts has been shown in Figure 1 .

\subsection{Wholesale Price Contract}

For the island electricity supply chain, according to the expanded newsvendor model, the intermittent renewable plant decides its optimal installed capacity and wholesale price according to the profit maximization goal. Therefore, the profit function of the intermittent renewable plant can be expressed as:

$$
\Pi_{g}^{T}\left(K^{T}, w^{T}\right)=w^{T} Q^{T}+\mu E\left(\min \left\{Q^{T}, \theta_{0} y K^{T}\right\}\right)-c K^{T}-g E\left(Q^{T}-\theta_{0} y K^{T}\right)^{+}
$$

According to Equation (5), the profit of the intermittent renewable plant is mainly composed of four parts. The first part represents the sales revenue of renewable energy electricity generated by the intermittent renewable plant; the second part represents the total amount of government subsidies to the intermittent renewable plant; the third part represents the installed cost of the intermittent renewable plant, since the cost of renewable energy electricity generation is mainly composed of fixed costs such as initial equipment investment, variable costs are negligible compared to fixed costs; the fourth part shows the cost of emergency electricity generation when renewable energy generation is insufficient.

According to the installed capacity and wholesale price of the intermittent renewable plant, combined with the demand of the electricity market, the ESC decides the optimal electricity purchased quantity, and sells the electricity to the customers through a series of operations such as voltage transformation and transmission. The expected profit function of ESC is as follows:

$$
\Pi_{r}^{T}\left(Q^{T}\right)=p E\left(\min \left\{X, Q^{T}\right\}\right)-w^{T} Q^{T}
$$

The profit function of the ESC mainly includes two parts: electricity sales revenue and electricity purchase costs.

Proposition 3: Under the wholesale price contract, there is a set of optimal solutions $\left(Q^{T *}, w^{T *}, K^{T *}\right)$ to maximize the expected profit of the intermittent renewable plant and ESC and satisfy: 


$$
\begin{gathered}
Q^{T *}=F^{-1}\left(\frac{p-w^{T *}}{p}\right) \\
\int_{0}^{\frac{Q^{T *}}{\theta_{0} K^{T *}}} y h(y) \mathrm{d} y=\frac{c}{\theta_{0}(g+\mu)} \\
w^{T *}=(g+\mu) H\left(\frac{Q^{T *}}{\theta_{0} K^{T *}}\right)-\mu
\end{gathered}
$$

By observing Equations (3) and (8), we can know that $\frac{Q^{*}}{\theta_{0} K^{*}}=\frac{Q^{T *}}{\theta_{0} K^{T *}}$, that is $Z^{*}=Z^{T *}$, which means the wholesale price contract will not affect the order level of the ESC. However, comparing Equations (2) and (7), it can be found that under the wholesale price contract, the optimal electricity purchased quantity $Q^{T *}$ of the retailer has changed, and $Q^{T *}$ will be affected by the wholesale electricity price $w^{T *}$, and negatively correlated with $w^{T *}$. That is, the increase in the wholesale electricity price will reduce the purchasing enthusiasm of the ESC. Therefore, this requires that when the intermittent renewable plant has the right to determine the wholesale price, a reasonable wholesale electricity price should be established, which can basically guarantee the benign supply of electricity on the island.

The expected profit function of the intermittent renewable plant and the ESC can be expressed as:

$$
\begin{aligned}
\Pi_{g}^{T}\left(K^{T}, w^{T}\right)= & w^{T} Q^{T}+\mu\left(\int_{\frac{Q^{T}}{\theta_{0} K^{T}}}^{1} Q^{T} \mathrm{~d} y+\int_{0}^{\frac{Q^{T}}{\theta_{0} K^{T}}} \theta_{0} y K^{T} \mathrm{~d} y\right) \\
& -c K^{T}-g \int_{0}^{\frac{Q^{T}}{\theta_{0} K^{T}}}\left(Q^{T}-\theta_{0} y K^{T}\right) \mathrm{d} y \\
\Pi_{r}^{T}\left(Q^{T}\right)= & p\left(\int_{m}^{Q^{T}} \frac{x}{n-m} \mathrm{~d} x+\int_{Q^{T}}^{n} \frac{Q^{T}}{n-m} \mathrm{~d} x\right)-w^{T} Q^{T}
\end{aligned}
$$

Therefore, we can get:

$$
\left\{\begin{array}{l}
w^{T *}=\frac{m\left(\mu-\sqrt{2} c \sqrt{\frac{g+\mu}{c \theta_{0}}}\right)+n\left(p-\mu+\sqrt{2} c \sqrt{\frac{g+\mu}{c \theta_{0}}}\right)}{2(n-m)} \\
K^{T *}=\frac{2(m-n)(g+\mu)+\sqrt{2}(n p-m \mu+n \mu) \theta_{0} \sqrt{\frac{g+\mu}{c \theta_{0}}}}{4 p \theta_{0}} \\
Q^{T *}=\frac{-m \mu+\sqrt{2} c(m-n) \sqrt{\frac{g+\mu}{c \theta_{0}}}+n(p+\mu)}{2 p}
\end{array}\right.
$$

Proposition 4: Under the wholesale price contract, the expected profit of the intermittent renewable plant, $\Pi_{g}^{T}\left(K^{T}, w^{T}\right)$ is a jointly concave function of the 
wholesale electricity price $W^{T}$ and the installed capacity $K^{T}$, the expected profit of the ESC, $\Pi_{r}^{T}\left(Q^{T}\right)$ is a concave function of the electricity purchased quantity $Q^{T}$.

Property 1: If the parameter $c$ satisfies the condition $c<2 \theta_{0}(g+\mu), w^{T *}$ has a negative correlation with $\mu, Q^{T *}$ has a positive correlation with $\mu$.

Property 1 indicates that under the wholesale price contract, the optimal wholesale price of the intermittent renewable plant and the optimal electricity purchased quantity of the ESC will be affected by government subsidies. Taking wholesale price as an example, under certain conditions, wholesale price will decrease with the increase of subsidy intensity. It can be seen from Equation (5) that the increase of government subsidy will increase this part of income of the intermittent renewable plant, which gives it an incentive to lower the price when making the optimal wholesale price decision. But when certain conditions are not met, the correlation may change. For example, when $c>2 \theta_{0}(g+\mu), w^{T *}$ and $\mu$ will lose the negative correlation, the practical significance is that the cost of investing in renewable energy electricity generation at this time is too high, which will make the intermittent renewable plant lack the motivation to invest in renewable energy. From this point of view, the development of renewable energy in the island environment cannot rely solely on government subsidies, the most fundamental thing is to improve the existing technical means to reduce the cost of electricity generation equipment.

Property 2: When the parameters satisfy the condition

$\sqrt{2}(n-m) \theta_{0} \sqrt{\frac{g+\mu}{c \theta_{0}}}+\frac{-m \mu+n(p+\mu)}{\sqrt{2} c \sqrt{\frac{g+\mu}{c \theta_{0}}}}>2(n-m), K^{T *}$ has a positive correlation with $\mu$.

Properties 1 and 2 show that under reasonable conditions, government subsidies have an important impact on the supply chain. Through government subsidies, the intermittent renewable plant has the space to reduce the wholesale price, and the reduction in wholesale electricity prices means cost reductions for ESC, therefore, it is willing to purchase more electricity, which in turn will cause the intermittent renewable plant to increase the installed capacity of renewable energy and ensure a larger-scale electricity supply. From this perspective, although government subsidies are aimed at the intermittent renewable plant, they will also benefit the ESC. To a certain extent, the government has played the role of risk transfer, it has assumed part of the risks of the intermittent renewable plant and ESC. The final result is that the island's electricity supply chain has become more reliable and stable. In fact, in China, the development of renewable energy electricity generation in the early stage is often inseparable from the strong support of the government. Government subsidies have guaranteed intermittent renewable plant gain a foothold in the electricity market. From this perspective, it is necessary and reasonable to consider government subsidies in the study of this paper. 
Comparing the strategies of wholesale price contract with the benchmark, we can easily get that $\Pi_{s c}^{T} \neq \Pi_{s c}, K^{T *} \neq K^{*}, Q^{T *} \neq Q^{*}$. Therefore, under the wholesale price contract, the supply chain has a double marginalization, and it can continue to be optimized. Consequently, in the next section the paper considers introducing a contract mechanism to optimize the supply chain.

\subsection{Revenue Sharing Contract}

In this part, the paper considers the revenue sharing contract that is common in supply chain. In this supply chain, the intermittent renewable plant and the ESC sign a revenue-sharing contract, and the ESC will give the proportion $\phi$ of its electricity sales income to the intermittent renewable plant, and the intermittent renewable plant will lower the wholesale electricity price. As the leader of the Stackelberg game, the intermittent renewable plant is able to request the ESC to share revenue, but the specific value of $\phi$ needs to be negotiated and determined by both parties. Under the revenue sharing contract, the Stackelberg model of the intermittent renewable plant and the ESC can be expressed as:

$$
\begin{aligned}
& \Pi_{g}^{S}\left(K^{S}, w^{S}\right)=w^{S} Q^{S}+\mu E\left(\min \left\{Q^{S}, \theta_{0} y K^{S}\right\}\right)-c K^{S} \\
&-g E\left(Q^{S}-\theta_{0} y K^{S}\right)^{+}+\phi p E\left(\min \left\{X, Q^{S}\right\}\right) \\
& \text { s.t. } \Pi_{r}^{S}\left(Q^{S}\right)=(1-\phi) p E\left(\min \left\{X, Q^{S}\right\}\right)-w^{S} Q^{S}
\end{aligned}
$$

The last term in Equation (13) is the revenue sharing part that the intermittent renewable plant obtains from the ESC, and the first item in Equation (14) represents the actual electricity sales revenue of the ESC after revenue sharing.

Proposition 5: Under the revenue sharing contract, there is a set of optimal solutions $\left(Q^{S *}, w^{S *}, K^{S *}\right)$ to maximize the expected profit of the intermittent renewable plant and ESC and satisfy:

$$
\begin{gathered}
Q^{S *}=F^{-1}\left[\frac{(1-\phi) p-w^{S *}}{p(1-\phi)}\right] \\
\int_{0}^{\frac{Q^{S *}}{\theta_{0} K^{S *}}} y h(y) \mathrm{d} y=\frac{c}{\theta_{0}(g+\mu)} \\
\left(\frac{1}{1-\phi}\right) w^{S *}=(g+\mu) H\left(\frac{Q^{S *}}{\theta_{0} K^{S *}}\right)-\mu
\end{gathered}
$$

According to $z^{S^{*}}=\frac{Q^{S^{*}}}{\theta_{0} K^{S^{*}}}$ and Equation (16) we can know, $z^{S^{*}}=z^{T *}=z^{*}$, which means under the revenue sharing contract, the order level of the ESC will not change. However, Equation (15) tells us that compared with the wholesale price contract, the optimal purchase quantity $Q^{S *}$ of the ESC under the revenue sharing contract will also be affected by the revenue sharing ratio $\phi$, and is positively correlated with $\phi$. Then we know that $K^{S *}$ is also positively correlated with $\phi$, which means that the revenue sharing contract can improve the 
purchasing enthusiasm of the ESC and the investment enthusiasm of the intermittent renewable plant to a certain extent. Besides, due to $z^{S *}=z^{T *}, \frac{1}{1-\phi}>1$, so after comparing Equation (17) and Equation (9) we can obtain $w^{S *}<w^{T *}$, in other words, $w^{S *}$ has a negative correlation with $\phi$.

The above information shows that under the revenue sharing contract, as the revenue sharing ratio increases, the intermittent renewable plant will have sufficient incentives to reduce the wholesale electricity price; and the purchase of electricity by the ESC will also increase. This is because of under the high revenue sharing ratio, lower wholesale electricity price means cost reductions for the ESC, which also increase its ability to resist risks under the condition of uncertain electricity demand. Therefore, the ESC will increase the purchases of electricity. While when the ESC' purchase of electricity increasing, the intermittent renewable plant will increase the installed capacity investment to increase electricity generation in order to increase revenue and reduce the cost of emergency electricity generation.

After substituting in the specific distribution, the optimal solution under the revenue sharing contract $\left(Q^{S *}, w^{S *}, K^{S *}\right)$ can be expressed as:

$$
\left\{\begin{array}{l}
w^{S *}=\frac{\left(2 g(m-n)-m \mu\left(-2+\sqrt{2} \theta_{0} \sqrt{\frac{g+\mu}{c \theta_{0}}}\right)+n\left(\mu\left(-2+\sqrt{2} \theta_{0} \sqrt{\frac{g+\mu}{c \theta_{0}}}\right)+(-1+\phi) \sqrt{2} p \theta_{0} \sqrt{\frac{g+\mu}{c \theta_{0}}}\right)\right)(-1+\phi)}{\sqrt{2}(m-n) \theta_{0} \sqrt{\frac{g+\mu}{c \theta_{0}}}(-2+\phi)} \\
K^{S *}=\frac{2(m-n)(g+\mu)+\sqrt{2} \theta_{0} \sqrt{\frac{g+\mu}{c \theta_{0}}}(n p-m \mu+n \mu)}{4 p \theta_{0}-2 p \phi \theta_{0}} \\
Q^{S *}=\frac{\sqrt{2} g(-m+n)+m \mu\left(-\sqrt{2}+\theta_{0} \sqrt{\frac{g+\mu}{c \theta_{0}}}\right)+n\left(\sqrt{2} \mu-(p+\mu) \theta_{0} \sqrt{\frac{g+\mu}{c \theta_{0}}}\right)}{p \theta_{0} \sqrt{\frac{g+\mu}{c \theta_{0}}}(-2+\phi)}
\end{array}\right.
$$

Proposition 6: Under the revenue sharing contract, the expected profit of the intermittent renewable plant, $\Pi_{g}^{S}\left(K^{S}, w^{S}\right)$ is a jointly concave function of the wholesale electricity price $W^{S}$ and the installed capacity $K^{S}$, the expected profit of the ESC, $\Pi_{r}^{S}\left(Q^{S}\right)$ is a concave function of the electricity purchased quantity $Q^{S}$.

Property 3: $w^{S *}$ has a positive correlation with $g, Q^{S *}$ has a negative correlation with $g$.

Property 3 shows that under the revenue sharing contract, the optimal wholesale electricity price of the intermittent renewable plant will be affected by the unit cost of emergency generation $g$. If the force majeure causes $g$ to increase, the intermittent renewable plant will tend to increase the wholesale electricity price when making optimal decisions. It can be seen from Equation (13) that after $g$ is increased, when renewable energy generation is insufficient and emergency electricity generation is required, the generator will bear higher electricity 
costs. Therefore, in order to balance this part of the loss, the intermittent renewable plant will increase the wholesale electricity price to protect its interests. On the other hand, for the ESC, the increase of wholesale electricity price means the increase of purchasing cost, and its instinct of avoiding risks makes it reduce purchasing electricity when making decisions.

Property 4: When the parameters satisfy the condition

$$
2(m-n)+\frac{-m \mu+n p+n \mu}{\sqrt{2} c \sqrt{\frac{g+\mu}{c \theta_{0}}}}>0, K^{S *} \text { has a negative correlation with } g \text {. }
$$

Generally, we think that when the unit cost of emergency electricity generation rises, the intermittent renewable plant will increase the installed capacity to reduce the risk of electricity shortage so that it can reduce or even avoid the high loss caused by insufficient electricity generation. However, this situation is not static. When making a decision, the intermittent renewable plant considers its final profit, not the profit or loss of a certain part of it. According to Equation (13), it can be found that increasing investment capacity will bring about new installation costs. If the risk stop loss caused by this increase in investment cannot be higher than the new installation cost, then the intermittent renewable plant will have a tendency to reduce installed capacity, so under certain conditions, $K^{S^{*}}$ has a negative correlation with $g$. Satisfying this condition is harsh, but it is possible. Therefore, when investigating the feasibility of renewable energy electricity generation on an island, it is necessary to fully consider various aspects such as policy, environment, and electricity demand, so as to ensure the smooth development and application of renewable energy.

\subsection{Revenue and Risk Sharing Contract}

In the previous part, this paper designed a revenue sharing contract. Through the revenue sharing contract, the intermittent renewable plant share part of the revenue of the ESC, so it will reduce wholesale electricity prices, while the increased purchase of ESC will stimulate intermittent renewable plant to increase the installed capacity. In this section, the author conducts further research on the basis of the revenue sharing contract. Trying to incorporate the risk sharing contract, and analyze the electricity supply chain under the revenue and risk sharing contract. Under the revenue and risk sharing contract, the intermittent renewable plant will not only bear all the uncertain output risks, but also the uncertain demand risks faced by ESC. The realization mechanism of risk sharing is that the intermittent renewable plan will compensate the unsold parts of the ESC.

Therefore, under the revenue and risk sharing contract, the expected profit function of the intermittent renewable plant and the ESC can be expressed as:

$$
\begin{aligned}
\Pi_{g}^{D S}\left(K^{D S}, w^{D S}\right)= & w^{D S} Q^{D S}+\mu E\left(\min \left\{Q^{D S}, \theta_{0} y K^{D S}\right\}\right)-c K^{D S} \\
& -g E\left(Q^{D S}-\theta_{0} y K^{D S}\right)^{+}+\phi p E\left(\min \left\{X, Q^{D S}\right\}\right)-v E\left(Q^{D S}-X\right)^{+}
\end{aligned}
$$




$$
\text { s.t. } \Pi_{r}^{D S}\left(Q^{D S}\right)=(1-\phi) p E\left(\min \left\{X, Q^{D S}\right\}\right)-w^{D S} Q^{D S}+v E\left(Q^{D S}-X\right)^{+}
$$

The last part of Equation (19) represents the risk cost borne by the intermittent renewable plant for the ESC, and the last part of Equation (20) represents the risk compensation that the ESC obtains from the intermittent renewable plant.

Proposition 7: Under the revenue and risk sharing contract, there is a set of optimal solutions ( $Q^{D S *}, w^{D S *}, K^{D S *}$ ) to maximize the expected profit of the intermittent renewable plant and ESC and satisfy:

$$
\begin{gathered}
Q^{D S *}=F^{-1}\left[\frac{(1-\phi) p-w^{D S *}}{p(1-\phi)-v}\right] \\
\int_{0}^{\frac{Q^{D S *}}{\theta_{0} K^{D S *}}} y h(y) \mathrm{d} y=\frac{c}{\theta_{0}(g+\mu)} \\
\frac{p\left(v-w^{D S *}\right)}{v-p(1-\phi)}=(g+\mu) H\left(\frac{Q^{D S *}}{\theta_{0} K^{D S *}}\right)-\mu
\end{gathered}
$$

According to $z^{D S *}=\frac{Q^{D S *}}{\theta_{0} K^{D S *}}$ and Equation (22) we know,

$Z^{D S *}=Z^{S *}=Z^{T *}=Z^{*}$, this shows that the revenue and risk sharing contract will not affect the order level of the ESC. However, compared with the revenue sharing contract, the optimal purchase quantity $Q^{D S *}$ of the ESC under the revenue and risk sharing contract will also be affected by the unit compensation $V$, and is positively correlated with $v$. Besides, $K^{D S *}$ is also positively correlated with $V$. The paper denotes $d=(g+\mu) H\left(\frac{Q^{D S *}}{\theta_{0} K^{D S *}}\right)-\mu$, and $D(v)=p\left(v-w^{D S *}\right)-d[v-p(1-\phi)]$, then we know $\frac{\partial D(v)}{\partial v}=p-d$, due to $\frac{\partial D(w)}{\partial w^{D S *}}=-p<0$, so when $p-d>0$, that is $p>(g+\mu) H\left(z^{D S *}\right)-\mu$, so we can get the wholesale electricity price $w^{D S *}$ is also positively correlated with $v$.

This shows that a higher proportion of risk sharing reduces the losses that ESC face due to excessive purchases, and in a sense reduces the risks of ESC. Combining with the lower wholesale price brought about by revenue sharing, under the revenue and risk sharing contract, as the risk share ratio increases, the ESC will increase its electricity purchased quantity, and when the electricity purchased quantity of the ESC increases, in order to ensure revenue, the intermittent renewable plant will increase the installed capacity of renewable energy. However, it is worth noting that, as the intermittent renewable plant that shares part of the risk, it may increase the wholesale price of electricity to deal with this contract.

The optimal solution under the revenue and risk sharing contract $\left(Q^{D S *}, w^{D S *}, K^{D S *}\right)$ can be expressed as: 


$$
\left\{\begin{array}{r}
\begin{array}{r}
-m\left(v\left(-v \theta_{0} \xi+\mu\left(-2+\theta_{0} \xi\right)\right)+p\left(-v \theta_{0} \xi(-2+\phi)+\left(-2+\theta_{0} \xi\right)(-1+\phi) \mu\right)\right) \\
+2 g(m-n)(p(-1+\phi)+v)
\end{array} \\
w^{D S *}=\frac{+n\left(v \mu\left(-2+\theta_{0} \xi\right)+p^{2} \xi \theta_{0}(-1+\phi)^{2}+p\left(\mu\left(-2+\theta_{0} \xi\right)(-1+\phi)+v \xi \theta_{0} \phi\right)\right)}{(m-n) \theta_{0} \xi(v+p(-2+\phi))} \\
K^{D S *}=\frac{2(m-n)(g+\mu)+\theta_{0} \xi(-m \mu+n p+n \mu)}{2 \theta_{0}(p(2-\phi)-v)} \\
Q^{D S *}=\frac{2 g(m-n)-m \mu\left(-2+\theta_{0} \xi\right)-n\left(\mu\left(2-\xi \theta_{0}\right)-p \theta_{0} \xi\right)}{\xi \theta_{0}(2 p-v-p \phi)} \\
\text { where } \xi=\sqrt{2} \sqrt{\frac{g+u}{c \theta_{0}}}
\end{array}\right.
$$

Proposition 8: Under the revenue and risk sharing contract, the expected profit of the intermittent renewable plant, $\Pi_{g}^{D S}\left(K^{D S}, w^{D S}\right)$ is a jointly concave function of the wholesale electricity price $w^{D S}$ and the installed capacity $K^{D S}$, the expected profit of the ESC, $\Pi_{r}^{D S}\left(Q^{D S}\right)$ is a concave function of the electricity purchased quantity $Q^{D S}$.

Property 5: $w^{D S *}$ has a negative correlation with $\theta_{0}, Q^{D S *}$ has a positive correlation with $\theta_{0}$.

According to $q=\theta_{0} y K$, the increase in the effective output coefficient $\theta_{0}$ means that the installed capacity required to achieve the same output electricity can be reduced, which will reduce the cost of the intermittent renewable plant. Therefore, the intermittent renewable plant has the incentive to reduce the wholesale electricity price. Similar to the previous part, the reduction of wholesale electricity prices will make the ESC more motivated to increase electricity purchased quantity.

Property 6: There exists a threshold $\theta_{0}=\frac{8 c(m-n)^{2}(g+\mu)}{(-n p+m \mu-n \mu)^{2}}$ such that, $K^{D S *}$ increases in $\theta_{0}$, when $\theta_{0}$ smaller than the threshold value, and vice versa.

Property 6 shows that the effective output coefficient of renewable energy electricity generation equipment will have an impact on the investment decision of intermittent renewable plant. Specifically, when the effective output coefficient of equipment is lower than the critical value, increasing the effective output coefficient will promote the intermittent renewable plant to increase the installed capacity; when the effective output coefficient of the equipment exceeds the critical value, increasing the effective output coefficient will reduce the installed capacity of the intermittent renewable plant. It can be seen from Property 5 that when $\theta_{0}$ increases, the ESC will increase the amount of electricity purchase, because the effective output coefficient has not reached a high level at this time, and the intermittent renewable plant will actively increase the installed capacity to meet the purchase demand of the ESC. When the effective output coefficient 
reaches a high level, it can be considered that renewable energy can guarantee the electricity output, so with the increase of the effective output coefficient, in order to reduce the cost, the intermittent renewable plant will reduce the installed capacity. This change actually reflects the risky decision of the intermittent renewable plant when facing the balance of electricity supply and demand.

\section{Discussions and Extensions}

In this section, the author carries out numerical experiments on the basis of the theoretical models in the previous sections. In the numerical experiments, the input data values have the best effect of multiple experiments, the relevant parameters can be set as follows: $p=1, c=0.1, \mu=0.15, g=0.8, \quad X \sim U\left(0,10^{4}\right)$, $y \sim U(0,1), \theta_{0}=0.5$.

\subsection{Sensitivity Analysis}

In the fourth section of this article, the author has analyzed the changes of equilibrium decision-making with different parameters under different contracts. Some of the conclusions are worthy of in-depth study. Therefore, in this section the author extends the discussion of some properties to multiple contracts, and combined with the image for specific analysis.

Numerical experiments have obtained the variation of optimal installed capacity $K$ of intermediate renewable power plants with effective output coefficient $\theta_{0}$ under the benchmark model and three contract conditions, as shown in Figure 2 below. It can be seen that the optimal installed capacity under the benchmark model and the three contracts shows a change situation of first increasing and then decreasing with the increase of the effective output coefficient, and the initial increase rate is much higher than the subsequent decrease rate. In reality, this effective output coefficient reflects the electricity generation efficiency of renewable energy electricity generation equipment, indicating that for

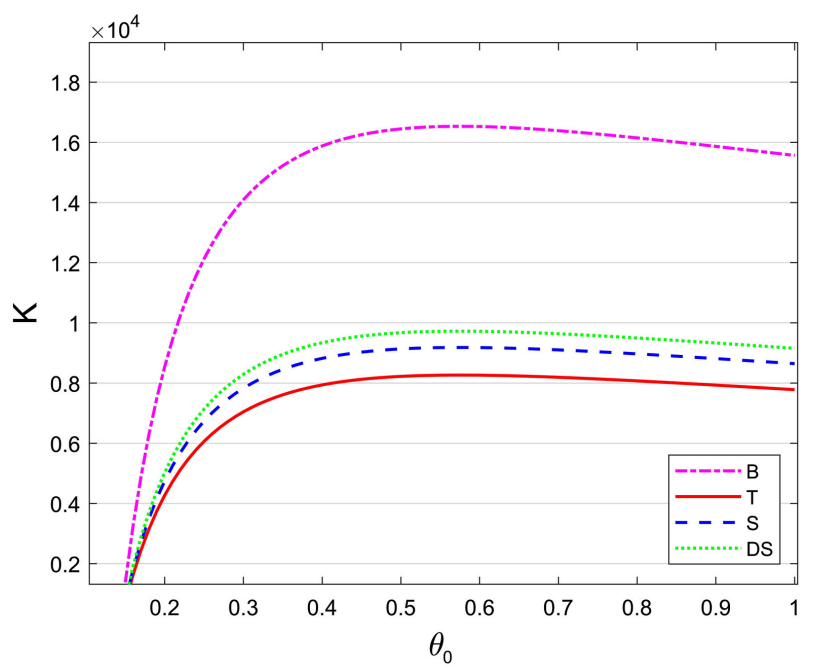

Figure 2. Changes of $K$ and $\theta_{0}$ under different contracts. 
island renewable energy electricity generation, to maintain a high investment capacity, it is not necessary to have equipment with higher electricity generation efficiency. In addition, according to Figure 2, under the same conditions, the installed capacity of the intermittent renewable plant under the benchmark model is always the highest, while the installed capacity of the generator under the wholesale price contract is always the lowest, and the revenue sharing contract and revenue and risk sharing contract is in the middle, and the revenue and risk sharing contract has a higher installed capacity than the revenue sharing contract. This demonstrates the effectiveness of the contract on the other hand, indicating that in an island environment, it is possible to increase the installed capacity of intermittent renewable plant and promote the development of renewable energy by introducing revenue and risk sharing contracts in the electricity supply chain.

Figure 3, obtained by mathematical software, shows the influence of the revenue sharing contract coefficient $\phi$ on the optimal purchase electricity $Q$ of the ESC under different contracts. Compared with the wholesale price contract, under the revenue sharing contract and the revenue and risk sharing contract, the optimal electricity purchased quantity of the ESC will increase, but it is still lower than the benchmark model. In addition, it can be seen that with the increase of $\phi$, the optimal electricity purchased quantity of ESC under the revenue sharing contract and the revenue and risk sharing contract is increasing. Although on the surface it seems that the higher the proportion of revenue that ESC give to intermittent renewable plant, the more revenue it will distribute, ESC make decisions based on its profits. Revenue sharing contracts can reduce the wholesale electricity prices, and for ESC, this means cost reduction, and as long as ESC sells electricity, there will be a price difference that can be earned, so ESC will increase purchases. Besides, it is not difficult to find that the growth rate of electricity purchased quantity under the two contracts is different, and the growth rate of the latter is higher than the former.

At the end of this section, this paper focuses on the impact of government subsidies on wholesale electricity prices under different contract conditions. Keeping other parameters unchanged, Figure 4 can be obtained by changing government subsidies. As shown in Figure 4, it can be found that with the increase of government subsidies, the optimal wholesale electricity prices of intermittent renewable plant under the three kinds of contracts show a downward trend. Among them, the decline trend under price wholesale contract and revenue sharing contract is close, while the downward trend under revenue and risk sharing contract is relatively gentle. This shows that under the same conditions, the impact of government subsidies on wholesale electricity price under the revenue and risk sharing contract is relatively small. This reminds the government to fully consider the contract environment of electricity supply chain and make targeted subsidies according to different contract environment. 


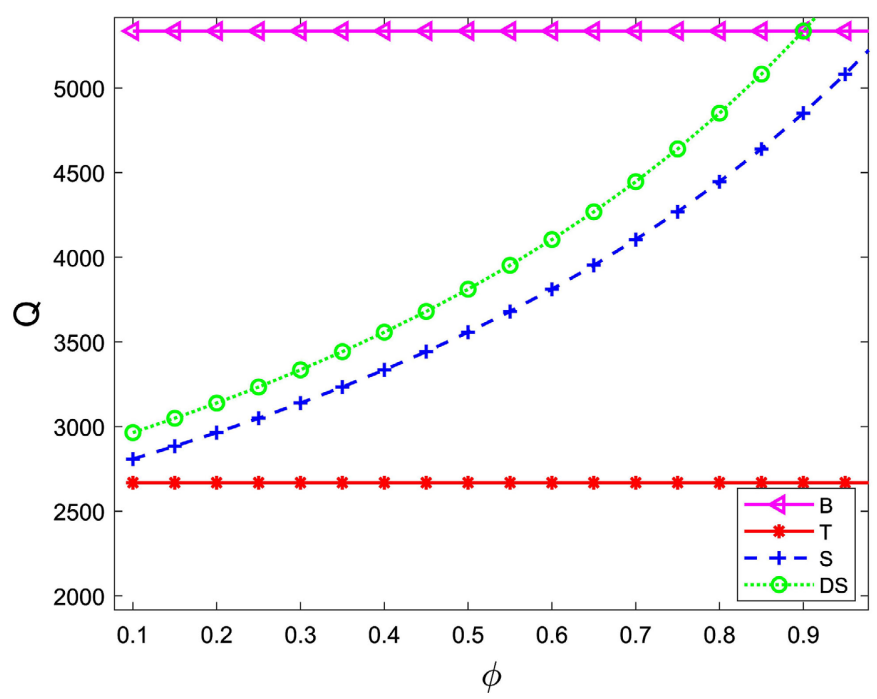

Figure 3. The influence of $\phi$ on Q under different contracts.

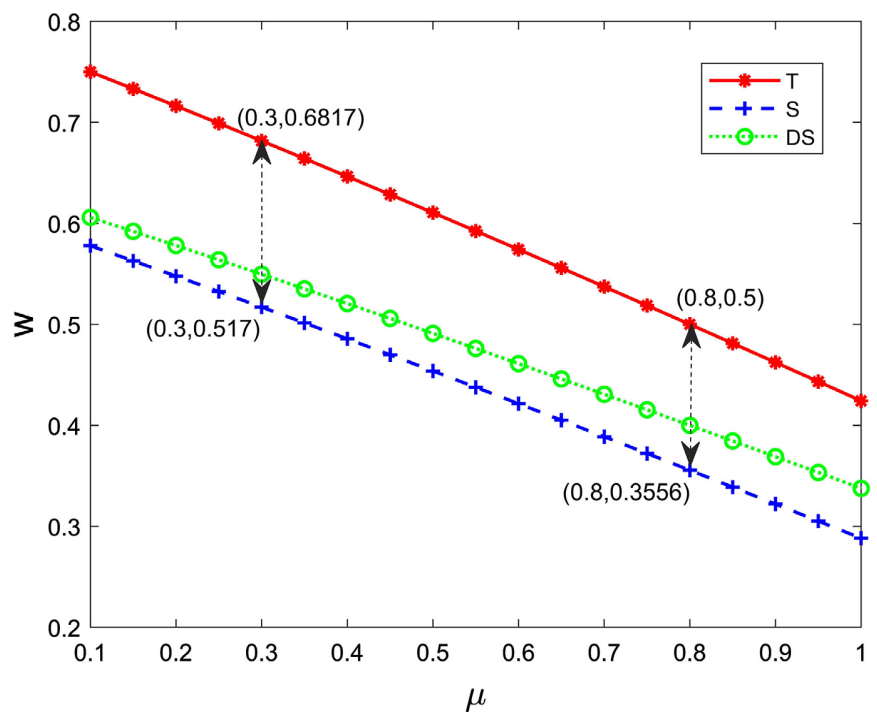

Figure 4. Changes of $\mathrm{w}$ with $\mu$ under different contracts.

\subsection{Profit Analysis}

Using the three-dimensional drawing function of mathematical software, the expected profit change of supply chain under the benchmark model can be obtained, as shown in Figure 5. It can be found that there is indeed a unique optimal solution $\left(Q^{*}, K^{*}\right)$ that maximizes the expected profit of the whole supply chain.

The optimal decision $\left(Q^{*}, K^{*}\right)=(5336,16445)$, and under this optimal decision, the optimal profit of the electricity supply chain reaches 1423 . This decision-making method integrates the upstream and downstream of the supply chain, so the wholesale price no longer has an impact on the supply chain, which can make the expected profit of the whole supply chain reach a higher level. But in reality, few companies are willing to do so. 


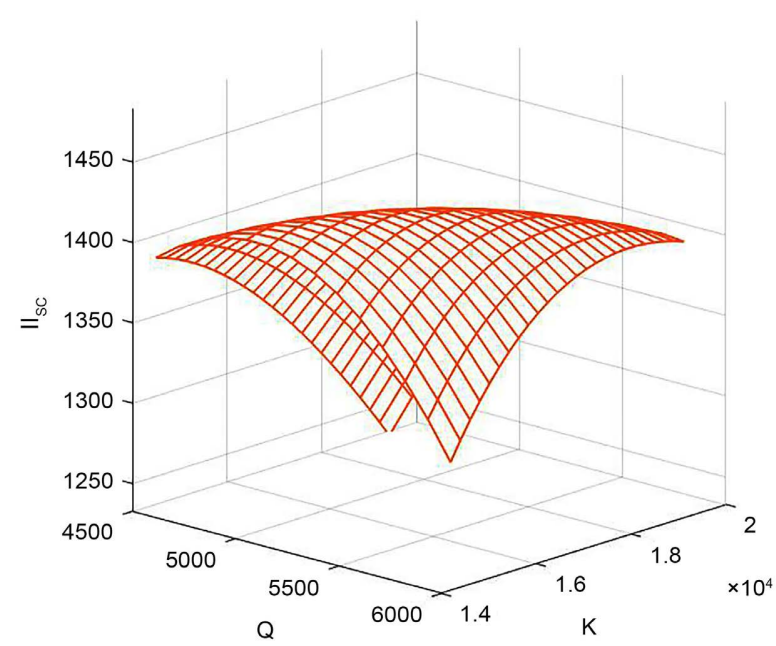

Figure 5. The expected profit change of the supply chain under the benchmark model.

In reality, the wholesale price contract is usually adopted between the upstream and downstream of the supply chain, and the wholesale price will have an important impact on the expected profits of both parties in the supply chain. Through numerical calculation, it can be obtained that the optimal solution $\left(w^{T *}, K^{T *}, Q^{T *}\right)=(0.73,8223,2668)$ and the maximum expected profit $\left(\Pi_{s c}^{T}, \Pi_{g}^{T}, \Pi_{r}^{T}\right)=(1067,703,364)$.

By comparing with the benchmark model, it can be found that the efficiency of the supply chain under the wholesale price contract has dropped significantly, so more effective contracts need to be designed to improve the efficiency of the supply chain.

Therefore, this paper designs the revenue sharing contract and the revenue and risk sharing contract. Without loss of generality, the author takes the revenue sharing coefficient $\phi=0.2$, and the risk sharing coefficient $v=0.1$. Therefore, through numerical calculation, we can get the optimal decision value and the optimal expected profit of the intermittent renewable plant and ESC and the maximum expected profit of the whole supply chain under the two contracts. Since the revenue and risk sharing contract is proposed on the basis of revenue sharing contract, after introducing the numerical value, by comparing the expected profit changes of intermittent renewable power plants under the two contracts, Figure 6 can be obtained:

According to Figure 6, it can be found that the expected profit of the intermittent renewable plant under the two contracts is a joint concave function of the wholesale electricity price $w$ and the installed capacity $K$, and under the same parameters, the expected profit of the intermittent renewable plant under the revenue and risk sharing contract is higher. In addition, it can be found that under the two contracts in Figure 6, the optimal decision of the intermittent renewable plant is similar in numerical value, which shows that the progressive effect of the progressive contract is different. 


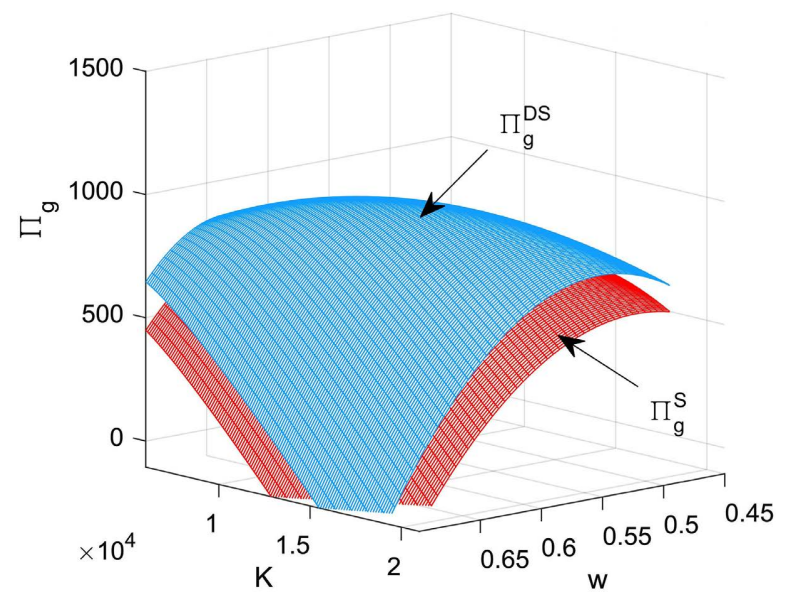

Figure 6. Change of expected profit of the intermittent renewable under two contracts.

Table 2. The equilibrium solution of the supply chain under different contracts.

\begin{tabular}{lllll}
\hline Symbol & SC & T & S & DS \\
\hline$Q^{*}$ & 5336 & 2668 & 2964 & 3139 \\
$w^{*}$ & - & 0.73 & 0.56 & 0.58 \\
$K^{*}$ & 16,445 & 8223 & 9136 & 9674 \\
$\Pi_{s c}$ & 1423 & 1067 & 1142 & 1182 \\
$\Pi_{g}$ & - & 703 & 782 & 832 \\
$\Pi_{r}$ & - & 364 & 360 & 350 \\
\hline
\end{tabular}

In order to more intuitively show the equilibrium solution of the supply chain under each contract, this paper summarizes the results of the previous numerical calculation, as shown in Table 2.

It can be seen from the table that under centralized decision-making, the expected profit of the whole supply chain is the largest, and the electricity purchased of the ESC and the installed capacity of the intermittent renewable plant are also the largest. Compared with the wholesale price contract, the efficiency of the supply chain is significantly improved under the revenue sharing contract. More importantly, the installed capacity and expected profit of the intermittent renewable plant also increase, which indicates that the revenue sharing contract can promote the development of renewable energy on the island. In addition, it can be found that the revenue sharing-demand risk sharing contract can further improve the efficiency of the supply chain and promote the development of renewable energy compared with the single revenue sharing contract. It is worth mentioning that in the electricity supply chain, the intermittent renewable plant is in a dominant position. The implementation of the contract mainly considers whether the revenue of the intermittent renewable plant can be increased, and the ESC has no right to decide, but the determination of the effective parameters of the contract needs to be negotiated by both parties. Therefore, although the 
revenue of the ESC under the latter two contracts will be reduced, this will not hinder the implementation of the contract.

\section{Conclusion}

At present, some researchers focus on renewable energy generation from the perspective of supply chain, but they tend to study inland areas and neglect remote islands. In order to analyze the electricity supply problem of remote islands, this paper studies the electricity supply chain problem of renewable energy as the main generator under the island environment. Different from the traditional electricity supply chain, intermittent renewable plants in an island environment are the leaders in a Stackelberg game model. Simultaneously, the study considers the actual situation of uncertainty in both the electricity yield and demand of renewable energy generation, and introduces government subsidies in the model. Taking the centralized decision as the benchmark, this paper studied the optimal decision and supply chain coordination of the intermittent renewable plant and ESC under the wholesale price contract, revenue sharing contract and revenue and risk sharing contract, analyzed the influence of some key parameters on the optimal decision and profit, and gave some suggestions.

Through modeling analysis and numerical verification, the main conclusions of this paper are as follows: the revenue and risk sharing contract can improve the efficiency of electricity supply chain and the income of intermittent renewable plant in the island environment. The revenue sharing contract is less effective, but still better than the wholesale price contract, and the increase of revenue sharing rate will reduce the wholesale electricity price of the intermittent renewable plant and increase the installed capacity of renewable energy, and meanwhile increase the electricity purchased quantity of the ESC. The increase of risk sharing rate will also increase the installed capacity of intermittent renewable plant and the electricity purchased quantity of the ESC, but it will give the intermittent renewable plant an incentive to increase the wholesale electricity price. In terms of parameter influence, intermittent renewable plant companies' investment in renewable energy capacity does not always decrease as the efficiency of their electricity generation equipment increases, when the efficiency of electricity generation equipment is low, the two are positively correlated. In addition, the government subsidy will make the electricity supply chain more stable, but the government should consider the contractual environment of the supply chain when subsidizing.

There are some possible directions for the future research. First, because current smart grid technologies are not mature enough, both intermittent renewable plant and ESC have an incentive to conceal relevant information, it is worth exploring the contract coordination with such asymmetric information, so as to make the research more reasonable. Second, although remote islands are far away from the mainland, there is the possibility of cooperation or competition between adjacent islands, so the model of single intermittent renewable plant 
and single ESC studied in this paper will no longer be applicable, Therefore, in subsequent studies, more research can be carried out into "many-to-one" or "many-to-many" situations. Finally, the study is just a theoretical analysis, thus collecting relevant data of renewable energy electricity supply chain on remote islands and conducting empirical analysis is also worth doing.

\section{Acknowledgements}

The author is grateful to the editor, the associate editor and the anonymous reviewers for their helpful comments and suggestions.

\section{Conflicts of Interest}

The author declares no conflicts of interest regarding the publication of this paper.

\section{References}

Adhikari, A., Bisi, A., \& Avittathur, B. (2020). Coordination Mechanism, Risk Sharing, and Risk Aversion in a Five-Level Textile Supply Chain under Demand and Supply Uncertainty. European Journal of Operational Research, 282, 93-107. https://doi.org/10.1016/j.ejor.2019.08.051

Agnolucci, P. (2007). The Effect of Financial Constraints, Technological Progress and LongTerm Contracts on Tradable Green Certificates. Energy Policy, 35, 3347-3359. https://doi.org/10.1016/j.enpol.2006.11.020

Begen, M. A., Pun, H., \& Yan, X. (2016). Supply and Demand Uncertainty Reduction Efforts and Cost Comparison. International Journal of Production Economics, 180, 125 134. https://doi.org/10.1016/j.ijpe.2016.07.013

Cachon, G. P., \& Lariviere, M. A. (2005). Supply Chain Coordination with RevenueSharing Contracts: Strengths and Limitations. Management Science, 51, 30-44. https://doi.org/10.1287/mnsc.1040.0215

Chong, A. Y. L., \& Zhou, L. (2014). Demand Chain Management: Relationships between External Antecedents, Web-Based Integration and Service Innovation Performance. International Journal of Production Economics, 154, 48-58.

https://doi.org/10.1016/j.ijpe.2014.04.005

Fang, X. (2018). Analysis of Double Marginalization Effect on the Wholesale Price Contract Coordination. Asia-Pacific Journal of Operational Research, 35, Article ID: 1840005. https://doi.org/10.1142/S0217595918400055

Frydrychowicz-Jastrzebska, G. (2018). El Hierro Renewable Energy Hybrid System: A Tough Compromise. Energies, 11, 2812. https://doi.org/10.3390/en11102812

Giri, B. C., \& Bardhan, S. (2017). Sub-Supply Chain Coordination in a Three-Layer Chain under Demand Uncertainty and Random Yield in Production. International Journal of Production Economics, 191, 66-73. https://doi.org/10.1016/j.ijpe.2017.04.012

Glock, C., Rekik, Y., \& Ries, J. (2020). A Coordination Mechanism for Supply Chains with Capacity Expansions and Order-Dependent Lead Times. European Journal of Operational Research, 285, 247-262. https://doi.org/10.1016/j.ejor.2020.01.048

Kong, L. C., Li, Z., Liang, L., \& Xie, J. P. (2017). RES-E Capacity Investment under Uncertain Renewable Energy Supply and Volatile Electricity Spot Price. Industrial Management \& Data Systems, 117, 1145-1165. https://doi.org/10.1108/IMDS-06-2016-0213 
Li, X., Li, Y. J., \& Cai, X. Q. (2013). Double Marginalization and Coordination in the Supply Chain with Uncertain Supply. European Journal of Operational Research, 226, 228-236. https://doi.org/10.1016/j.ejor.2012.10.047

Luo, C. L., Tian, X., Mao, X. B., \& Cai, Q. (2018). Coordinating Supply Chain with BuyBack Contracts in the Presence of Risk Aversion. Asia-Pacific Journal of Operational Research, 35, Article ID: 1840008. https://doi.org/10.1142/S0217595918400080

Mardan, E., Amalnik, M. S., \& Rabbani, M. (2015). An Integrated Emergency Ordering and Production Planning Optimization Model with Demand and Yield Uncertainty. International Journal of Production Research, 53, 6023-6039. https://doi.org/10.1080/00207543.2015.1008109

Nielsen, I. E., Majumder, S., Sana, S. S., \& Saha, S. (2019). Comparative Analysis of Government Incentives and Game Structures on Single and Two-Period Green Supply Chain. Journal of Cleaner Production, 235, 1371-1398. https://doi.org/10.1016/j.jclepro.2019.06.168

Scheller-Wolf, A., \& Tayur, S. (2009). Risk Sharing in Supply Chains Using Order BandsAnalytical Results and Managerial Insights. International Journal of Production Economics, 121, 715-727. https://doi.org/10.1016/j.ijpe.2009.02.008

Tsay, A. A. (1999). The Quantity Flexibility Contract and Supplier-Customer Incentives. Management Science, 45, 1339-1358. https://doi.org/10.1287/mnsc.45.10.1339

Wu, D., Chen, J. H., Li, P., \& Zhang, R. J. (2020). Contract Coordination of Dual Channel Reverse Supply Chain Considering Service Level. Journal of Cleaner Production, 260, Article ID: 121071. https://doi.org/10.1016/j.jclepro.2020.121071

Xie, J. P., Wei, L. H., Zhang, W. S., Xia, Y., \& Li, J. (2019). A Responsive Pricing Grid Operator Sourcing from Competing Generators under Uncertain Supply and Demand. Sustainability, 11, 4061. https://doi.org/10.3390/su11154061

Xie, J. P., Xia, Y., Liang, L., Zhang, W. S., \& Shi, M. H. (2018). Pricing Strategy for Renewable Energy Source Electricity in the Competitive Hybrid Electricity Market. Industrial Management \& Data Systems, 118, 1071-1093. https://doi.org/10.1108/IMDS-08-2017-0341

Xu, J. P., Jiang, W., Feng, G. Z., \& Tian, J. (2012). Comparing Improvement Strategies for Inventory Inaccuracy in a Two-Echelon Supply Chain. European Journal of Operational Research, 221, 213-221. https://doi.org/10.1016/j.ejor.2012.03.008

Yu, B. Q., Wang, J., Lu, X. M., \& Yang, H. T. (2020). Collaboration in a Low-Carbon Supply Chain with Reference Emission and Cost Learning Effects: Cost Sharing versus Revenue Sharing Strategies. Journal of Cleaner Production, 250, Article ID: 119460. https://doi.org/10.1016/j.jclepro.2019.119460 